\title{
O Serviço Social entre a prevenção e a promoção da saúde: tradução, vínculo e acolhimento
}

\section{Social Work between prevention and health promotion: translation, attachment and reception}

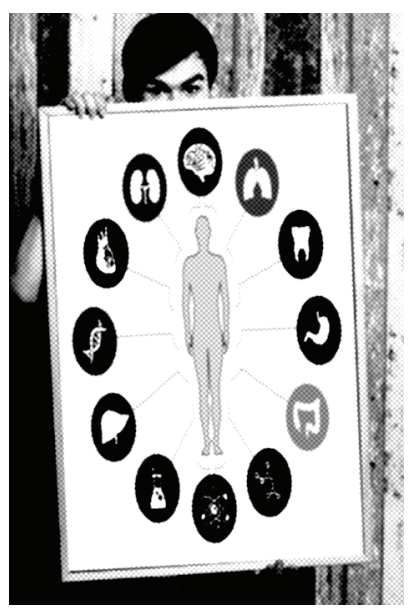

Francis Sodré*

Resumo: Este artigo aborda o trabalho dos assistentes sociais na atenção primária em Vitória-ES. Interessa-nos refletir sobre as ações de "promoção à saúde" realizada pelos assistentes sociais. Diferenciamos duas abordagens na saúde pública: a prevenção de doenças e a promoção da saúde. Quando centrado nas atividades de promoção, o trabalho é voltado para a produção de vínculos e acolhimento. "Promover" à saúde também se apresenta como um modelo de educação formal, centrado em salas de aula nas escolas, e o profissional apresenta-se como aquele que "ensina" boas práticas, hábitos ou comportamentos.

Palavras-chave: Serviço Social. Promoção à saúde. Saúde coletiva.

\begin{abstract}
This article is about the social workers's work in primary attention in Vitória/ES. We are interested in thinking about the actions towards "promoting health" social workers undertake. We make a distinction between two approaches in public health: prevention of diseases and promotion of health. When related to promotion of health, the work is directed to the production of attachment and reception. "To promote" health is also a model of formal education, centered in classrooms in schools, and the professional is the one who "teaches" good practices, habits or behaviors.
\end{abstract}

Keywords: Social Work. Promotion of health. Public health.

* Assistente social, doutora em Saúde Coletiva, professora do departamento de Serviço Social e do Programa de Pós-Graduação em Saúde Coletiva da Universidade Federal do Espírito Santo (Ufes), Vitória-ES, Brasil.E-mail: francisodre@uol.com.br. 


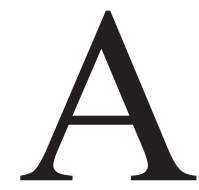
estratégia de saúde da família como parte da proposta de atuação na atenção primária da saúde pública trouxe desafios aos assistentes sociais envolvidos nas práticas de saúde em equipes multidisciplinares. Interessa-nos aqui desenvolver um estudo sobre a proposta de inversão do modelo hospitalar trazida pelo SUS, por meio de ações de prevenção e promoção da saúde nas unidades básicas de saúde. $\mathrm{O}$ assistente social como parte da equipe considerada "de apoio" - profissionais que dão suporte à equipe mínima de saúde nas unidades - passa a ser exigido por cumprir atividades em nome da promoção da saúde. Junto a isso existe também uma exigência do Ministério da Saúde brasileiro, que diferencia atividades preventivas de doenças de outras que são promotoras de saúde. Discutiremos aqui a relação entre a prevenção e a promoção da saúde nas práticas dos assistentes sociais de unidades de saúde a partir de três momentos distintos: a) o olhar sobre o território da saúde pública, b) a família como foco de intervenção e c) o trabalho do assistente social nas ações de prevenção e promoção da atenção primária à saúde.

Nessa pesquisa exploramos as experiências de trabalho de doze assistentes sociais (duas de cada uma das seis microáreas regionais de saúde da cidade de Vitória (ES). ${ }^{1}$ Elegemos os profissionais com mais tempo de atuação nas unidades de saúde para realizarmos uma entrevista semiaberta sobre o trabalho dos assistentes sociais com atividades de promoção da saúde. As entrevistas foram gravadas, transcritas e analisadas por conteúdo temático com a concordância dos profissionais entrevistados.

\section{0 território e a saúde pública}

A implantação do Sistema Único de Saúde colocou desafios importantes à prática dos profissionais da saúde pública no Brasil. A reordenação dos serviços exigiu a inserção de atividades de vigilância epidemiológica e sanitária com ampla produção de informações e mapeamentos da população sobre o seu perfil de morbimortalidade. Na atenção primária à saúde isso representou investir em ações de prevenção de doenças e promoção da saúde que investigassem microscopicamente a vida, os hábitos e os costumes de vida das populações através da inserção dos

1. Vitória possui aproximadamente 330 mil habitantes e é dividida em seis microáreas de saúde: região Central, Continental, Forte São João, São Pedro, Maruípe e Santo Antônio. 
programas voltados à atenção à saúde das famílias, que, posteriormente veio a ser considerada uma "estratégia" de intervenção do sistema no âmbito local dos territórios de saúde.

A primeira preocupação foi esquadrinhar os territórios. Para explorar o âmbito local da vida exigiu-se o exame apurado dos hábitos e do cotidiano dos moradores. Nos moldes da medicina urbana francesa do século XVII, ${ }^{2}$ a estratégia de saúde da família previu que o âmbito local, suas dinâmicas e o fluxo de deslocamento dos seus moradores continham a matéria-prima para a intervenção dos profissionais de saúde. Era preciso pensar o cotidiano do local, o território, e investir em medidas de impacto que interferissem na circulação e no deslocamento dos habitantes.

Desde a implantação do SUS, a vida na cidade foi envolvida de cuidados. A dinâmica urbana se tornou passível de ser examinada. O fluxo e a circulação dos seus moradores tornaram-se foco de averiguação para estudos minuciosos de rotinas que pudessem interferir nos quadros sanitários em todo o país. A população tornou-se muito numerosa nas grandes cidades, e pouco a pouco as diferentes realidades sociais do Brasil se tornaram cada vez mais complexas para uma intervenção julgada eficaz no quadro político-sanitário.

Essa preocupação não pode ser considerada de tipo novo, pois que desde o início da idade moderna existiam as medidas de contenção das populações em sua territoriedade. A contagem das casas, das pessoas, das ruas, dos riscos de adoecimento ou insalubridade, desde o século XVII na Europa, foi mapeada com o intuito de transformar a cidade em um grande banco de estatísticas sobre o cotidiano. Daí a necessidade do esquadrinhamento das cidades e bairros. A cidade deveria ser inspecionada, rua por rua, percorrida com um olhar permanente e controlada pelo registro de todos os seus fenômenos de saúde por meio de uma incessante vigilância. Primeiro, por razões econômicas: o crescimento da cidade, suas relações comerciais e o surgimento da indústria nos grandes centros e suas consequências nas mudanças urbanas. Segundo, por razões políticas: o aparecimento de múltiplos tipos de trabalhadores, o controle dos movimentos sociais urbanos e a divisão do território por classes sociais - uma espécie de segregação social e espacial que poderia vir a gerar conflitos.

2. A medicina urbana francesa preocupou-se no século XVII em conter os movimentos locais de questionamento às ações de governo com as populações que passavam por condições sociais degradantes de vida. Controlou-se o movimento das pessoas, seu deslocamento, o fluxo da água e esgoto, bem como o perfil de vida e morte das pessoas com ações autoritárias, sem diálogos com as populações. Sobre isso ver Foucault, 2000. 
O interessante é observar que o primeiro objetivo desse olhar sobre a cidade é que a aglomeração de pessoas e a confusão das rotinas tornam-se um perigo para o tecido urbano. Em tempos atuais, a atenção primária à saúde apresenta a necessidade de verificar as coisas, os objetos, os elementos que circulam pela cidade juntamente com as pessoas. Essa medida de exame sobre o "território salubre" torna-se o primeiro pilar da saúde da família como estratégia desse nível de atenção à saúde pública.

A mobilidade urbana, o movimento das pessoas nos bairros, a construção de edificações, o movimento dos veículos e o fluxo por eles gerado passam a ser foco de estudo para a saúde pública, dividida e mapeada geograficamente. A primeira ação, portanto, é voltada para a observação da saúde como pertencente a um distrito sanitário (a cidade pode ser insalubre e por isso deve ser mapeada por uma geografia humana e pelos seus "riscos"). Esse território contém o hábito e o cotidiano das pessoas. Dessa forma, torna-se um objeto de estudo e intervenção para a saúde pública.

\section{A intervenção com as famílias}

O segundo foco de ação é a família. A estratégia de saúde da família contém a preocupação com os costumes. A família, como conceito elitista, foi revisitada em sua raiz pelo SUS. O modelo nuclear não atendia mais a parâmetros que ditavam ações pautadas pelo atendimento à ginecologia para a mãe, a medicina do trabalho para o pai e a puericultura para as crianças. Ainda que esse modelo tradicional (e conservador) seja a orientação central dos padrões de moralidade para o Estado, a estratégia de saúde da família teve que ser reorientada em sua fonte mais primária: o costume familiar da grande cidade industrializada foi invadido pela violência, pobreza e hábitos de higiene e alimentação que transformaram a ordem elitista em uma "desordem" social.

A família nuclear foi substituída pelo modelo "solto", flexível, sem ordem, sem laços entre consanguíneos, questionando a centralidade do patriarca, com longevidade estendida e, muitas vezes, pautada por valores de consumo e acostumada à intervenção do Estado em seus hábitos mais domésticos. Para a estratégia de saúde da família (ESF), a "organização" das famílias visando a formação da prole, a educação dos mesmos e a conservação das crianças foi um embate a ser travado em cada território. As famílias empobrecidas, mapeadas na implantação da 
ESF, são marcadas pela miséria, focalizadas nas políticas de assistência social, habituadas a sobreviver pelos laços de solidariedade e ser objeto de ação do Estado somente por meio de políticas de moralização.

Costa (2004) relata que a criação da medicina de família no século XVIII no Brasil foi a criação de uma atuação profissional tirânica. O modelo da medicina familiar, que hoje se expandiu a muitas profissões de saúde, deu origem a profissionais que fazem da saúde das populações objeto de ação despótica.

Todo esse caldo de história não se perde reinventando modelos. A Estratégia de Saúde da Família traz consigo a obrigatoriedade de reorientação de modelos de serviços pautados unicamente na centralidade hospitalar; mas também se reorienta por meio de uma sociedade altamente medicalizada e com costumes que evocam a busca por um corpo perfeito - tanto em sua estética, quanto na necessidade de tornar este corpo apto ao trabalho, pronto a produzir, livre de adoecimentos. Desta maneira, a ação do Estado ainda que autoritária, encontra novos valores relacionados à produção de saúde.

Eis então a fórmula para a intervenção da atenção primária: território e família. Essa fórmula é a mesma do Brasil colonial quando foi implantado o primeiro olhar social sobre a saúde pública no Brasil (Costa, 2004). O que agora pretendemos compreender é como e de que forma, cria-se um discurso reformado desse método com nome de "promoção à saúde" e de que forma esta prática é vivida por assistentes sociais que atuam na atenção básica do SUS.

\section{Do método de "prevenir" ao modo de "promover"}

A prevenção de doenças está correlata ao campo da epidemiologia e, desta forma, se detém a evitar o adoecimento a partir de um conhecimento de práticas cuja meta central é diminuir e evitar doenças, principalmente imunizando indivíduos (Czeresnia, 2003). De acordo com Buss (2003), evitar que as pessoas adoeçam é o ponto principal das técnicas preventivas.

Quando dizemos que algo pode ser evitável, conhecemos o agente causador. Desta forma, afirmamos conhecer "o risco", o que significa conter aquilo que a priori determina o surgimento de uma doença. Então podemos afirmar que iremos prevenir, se antecipar, agir antes que a doença se instale. Os trabalhos de prevenção são de antecipação à doença, combatendo seus possíveis agentes causadores. 
Essa atividade, portanto, está diretamente relacionada à figura do médico profissional central às práticas de prevenção. A centralidade em um profissional de saúde direcionará o cuidado, principalmente aos "grupos-alvo", "grupos de risco" ou "grupos vulneráveis", tais como diabéticos, obesos, hipertensos. Para estes deverá ser criada uma estratégia que usará de argumentos de persuasão para evitar agravos e sequelas das enfermidades de que são portadores. $\mathrm{O}$ foco aqui é fazer com que as pessoas mudem seu modo de vida, não como escolha, mas como imposição de uma norma sanitária.

Por outro lado, quando objetivamos a promoção da saúde, essa prática é avaliada socialmente de forma positiva pelos profissionais da saúde. Os trabalhos de promoção à saúde não se tornam objetos apenas de profissionais da área médica, mas ao contrário, deverão favorecer o envolvimento e a participação de todas as pessoas, as organizações da sociedade civil, as associações de bairros etc. Nessa perspectiva, dar-se-á ênfase não apenas à saúde, mas toda uma rede de temas diversos deverá ser abordada a fim de criar possibilidades de mudanças nos modos de vida, comportamentos e no ambiente em que vivem e convivem as pessoas. Esse enfoque deve abranger as instâncias municipal, regional e federal, além de incentivar a intersetorialidade das ações.

Para atuar com promoção da saúde é preciso associar os saberes técnicos aos saberes populares, para, agindo em ações intersetoriais, gerar o protagonismo dos sujeitos levando, consequentemente, a um nível ótimo de vida (Buss, 2003). Portanto, a promoção da saúde é um conceito em construção por meio de ações que se completam entre a prevenção e a promoção, de tal forma que uma não venha a anular a outra e o saber técnico dialogue com o saber popular, proporcionando a criação de um "novo saber" que não tem parâmetros ou pressupostos sobre ele.

De acordo com Czeresnia (2003), pela promoção é possível fortalecer as capacidades individuais e também coletivas, proporcionando maior capacidade de escolhas e atitudes sobre a própria vida. Segundo a autora, promoção não é apenas questão de existência, é questão de qualidade de existência. Grande parte dos programas de promoção da saúde passa pela mudança de comportamentos e hábitos de vida. Essa confusão entre os termos ocorre por ser a promoção um campo novo, ao contrário da prevenção, que já está consolidado entre as práticas de saúde. A raiz da questão pauta-se no entendimento sobre a saúde não apenas como ausência de doenças, mas é analisada a partir de vários outros aspectos da vida de uma pessoa ou de um grupo antes de considerá-los ou não saudáveis.

Por isso podemos afirmar que não há e não haverá um modo correto de produzir ações de promoção à saúde. Ela não está contida em protocolos ou manuais 
do sistema público de saúde com a maneira certa ou errada. A promoção da saúde resguarda aspectos da educação em saúde, baseada na tecnologia do diálogo que produz conhecimento em ato, no momento do encontro. Sendo assim, trata-se de uma ação baseada no acesso ao serviço de saúde como aquele que irá "produzir junto" conhecimentos, ações, vinculações e interpretações sobre o modo de produzir saúde.

Não temos dúvidas que na política pública o que motiva a discussão em torno do tema é um interesse ou uma necessidade de diminuir os custos elevados que vêm sendo contabilizados na atenção à saúde. Esse enfoque pode atender a ideais capitalistas, pois que buscam efetivar a autonomia das pessoas para, dessa forma, possibilitar uma menor necessidade de ação do Estado.

Por outro lado, autores como Buss (2003) ressaltam ainda que o movimento em torno do tema coincide com os interesses do desenvolvimento sustentável da Agenda 21, que considera não só os aspectos internos da vida, mas o ambiente onde ele vive e se relaciona.

Para dar conta desse amplo leque de aspectos da vida toma-se o tema "promoção da saúde" com conceitos discutidos nas duas últimas décadas, principalmente no Canadá, Estados Unidos e alguns países da Europa. Aconteceram nesse lapso de tempo várias conferências quando o tema foi pensado e discutido em encontros que ocorreram em Ottawa (1986), Adelaide (1988), Sundsval (1991), Jacarta (1997), México (2000) e também na Conferência Internacional de Promoção da Saúde realizada no Brasil em 1992 (Buss, 2003).

\section{O Serviço Social entre a prevenção e a promoção da saúde}

Os assistentes sociais relatam diferentes formas de prevenir ou promover nas ações que desenvolvem em saúde. Quando são solicitados para explorar as atividades de prevenção, respondem com clareza e precisão, pois compreendem a atuação de combate ao um "risco" específico, referem-se a doenças que requerem uma atuação que se antecipe e que não deixe avançar um quadro preexistente ou em vias de aumento de número de casos.

O mesmo não se aplica quando questionados a definir o que seja uma atividade de promoção. Na mistura das respostas, que muitas vezes acontece, dizem que promover é algo amplo, maior e que busca uma mudança de hábitos ou comportamentos. 
A promoção da saúde quase sempre é referida como uma atividade de educação em saúde pelos assistentes sociais. Referem-se às atividades dialógicas, como as reuniões com a comunidade, mas também mencionam as palestras - como forma de transmissão de conhecimentos considerados "científicos" aos usuários dos SUS.

Evidencia-se que os assistentes sociais permitem entender a educação em saúde por duas vertentes de atuação: 1) algo que se dá em ato, no momento do encontro como troca de saberes e a capacidade de dialogar sobre comportamentos, estilos de vida, dúvidas em relação a determinada atitude. Proporciona acolhimento e muitas vezes "traduz" para a linguagem dos usuários uma ação desejada pelas diretrizes ministeriais como uma "atitude saudável". Neste sentido, a "tradução" realizada pelo assistente social coloca-se como um papel a ser desempenhado na qualidade de um interlocutor entre as ações educativas propostas pela saúde pública e o conhecimento que se quer transformar em ação pelos usuários. Outra compreensão deriva de um entendimento sobre educação em saúde como: 2) uma concepção que se resume à transmissão de conhecimento científicos. O usuário do SUS é visto com um receptor de informações. Os assistentes sociais elegem um tema específico a ser tratado em reuniões, atividades grupais ou outra ação que seja coletiva, denominada "atividades de educação em saúde", pois envolve o trabalho com a linguagem e uso de recursos professorais: projeção de slides, cadeiras em fila, sala de aula formal ou auditório, quadro, cartazes ou imagens para repassar um conhecimento sobre determinado tema. Muitas vezes esse suposto tema não é de interesse dos usuários presentes nas reuniões, que estão ali para cumprir um pré-requisito de determinada atividade - como os critérios de inclusão do programa Bolsa Família do governo federal - requisito considerado obrigatório (uma condicionalidade).

A reunião do programa Bolsa Família se torna o espaço de muitos assistentes sociais atuam na atenção primária e se colocam como interlocutores da ação ministerial em sua relação com a comunidade. Muitos profissionais entendem que um programa que gere renda contém em si a ação de promoção da saúde, visto que essa ação desencadeará inúmeras outras possibilidades de gerar autonomia e liberdade para o consumo de mercadorias que proporcionarão maior qualidade de vida, acesso a determinados alimentos, medicamentos, vestuários etc. No entanto, o formato como são realizados os encontros coletivos para cumprir as condicionalidades do programa muitas vezes é desvirtuado pelos próprios assistentes sociais.

Encontramos profissionais que usam os encontros do programa Bolsa Família como um espaço para realizar reuniões sobre doenças, como diabetes, tuberculose, 
hipertensão ou tabagismo. Muitas vezes o público presente a essas reuniões não era portador de nenhuma dessas doenças e colocavam-se sentados, em lugar de submissão ao profissional de saúde, para cumprir a condicionalidade do programa e continuar recebedores dos direitos que o Bolsa Família proporciona. Quando perguntados ao final das reuniões, os usuários não entendiam os motivos pelos quais tiveram que ouvir uma "palestra" sobre um tema que não se relacionava com suas vidas, não encontravam sentido na ação, mas diziam compreender que aquilo era realizado para cumprir um protocolo. Por outro lado, os assistentes sociais faziam mecanicamente uma palestra sobre um tema escolhido, muitas vezes com um convidado especialista no assunto abordado (por exemplo, um enfermeiro com especialização em controle de diabetes) e assim finalizavam a ação como quem atendeu um quesito do programa estabelecido pelo governo federal. O papel do especialista e também do assistente social reproduzem, nesse sentido, uma hierarquização do saber biomédico, em que cada profissional se responsabiliza por sua "clínica", abordando temas específicos recortados por agravo ou por risco à saúde. Tratam de temas que se correlacionam com o surgimento de doenças, repetindo receitas e hábitos que julgam difundir como "corretos". Isso também se aplica a temas como planejamento familiar ou uso de drogas, pregando práticas de controle em geral autoritárias sobre a mulher que frequenta a unidade de saúde e a abstinência como única alternativa ao uso de drogas consideradas ilícitas.

Os espaços de encontro com os usuários da saúde são poucos quando realizados coletivamente. Sabemos que existe uma "métrica" que calcula a ação dos assistentes sociais por produção em determinados serviços de saúde, mas a utilização desses espaços que se denominam "educação em saúde" como um repasse de informação sem uma perspectiva de diálogo com a comunidade é uma ação frequente.

Nesse caso, os assistentes sociais denominam esse encontro como uma ação de "promoção da saúde", associado ao espaço de "educar" para hábitos e comportamentos saudáveis. Promover, assim, passa a ser entendido como uma ação ampla, tanto pelo seu lastro coletivo de abordagem quanto por requerer uma ação que o profissional se expõe no uso da linguagem perante muitos usuários do SUS e outros profissionais com quem dividem as atribuições do "fazer saúde" nas unidades de saúde municipais.

Frequentemente, essa ação tem um foco direcionado para a ação individual (e individualizante), no esforço do indivíduo em mudar seu pensamento ou atitude - mesmo que aconteça por meio de uma abordagem grupal. Ou seja, ainda que reunidos para uma ação coletiva, o foco do assistente social está na atitude direcionada ao indivíduo, podendo ser uma reunião com abordagens grupais, mas espe- 
rando uma ação que seja uma resposta de indivíduo por indivíduo. Além disso, a palestra é uma forma de abordagem que coloca lugares estabelecidos: um indivíduo sabe e detém o poder da transmissão do conhecimento; outros não sabem e colocam-se no lugar da recepção de informações. Isto aborta qualquer perspectiva dialógica em um trabalho de abordagem coletiva.

Essa relação está atravessada pela concepção da prevenção embutida na promoção da saúde. Existe um entendimento que "promover" significa não deixar desenvolver uma doença ou não deixar potencializar um risco, e isto se define como prevenir, mas aparece denominado pelos assistentes sociais como "promoção da saúde". A preocupação pela adoção de "comportamentos saudáveis" baseia-se na premissa de que boa parte dos problemas de saúde está relacionada com estilos de vida. Dessa forma, ações ligadas às mudanças das condições de existência, como acesso à educação, à moradia e ao saneamento, não são encaradas como relevantes nesse processo. Podemos dizer que essa concepção de saúde relaciona-se à ideia de ausência de doenças e reflete a primazia da ação individual. O foco da ação passa a ser, então, o indivíduo e seus hábitos, como se fosse possível isolá-lo de seu contexto social, econômico e político (Santos et al., 2010).

A relação que reforça e faz repetir essa concepção de abordagem em saúde pelo assistente social se faz presente no modelo biomédico de atenção à saúde. Os assistentes sociais trazem de forma frequente em seu discurso a necessidade de conversar com a equipe sobre o entendimento do que seja saúde ou doença. Veem-se no lugar ainda repetido daqueles profissionais que recebem toda e qualquer demanda que não tem resposta imediata pelos profissionais de formação biomédica. E aquilo que não apresenta uma resposta imediata ou um diagnóstico fechado pelos profissionais que usam o jaleco branco é dirigido aos assistentes sociais como "uma questão que é social" e, portanto, precisa de um encaminhamento ou ação do profissional que não consegue resolver a demanda de forma a fechar um diagnóstico, anamnese, exame ou evidência numérica que se torne uma estatística epidemiológica.

Está contido nesse diálogo (não dito e não verbalizado diretamente) uma concepção de saúde pública que se associa à formação de pequenos prontos-atendimentos ou mini-hospitais dentro das unidades de saúde. Entende-se por social tudo aquilo que não tem resposta imediata por parte da equipe considerada "básica" (médico, enfermeiro, dentista e agente de saúde). Há repetição de um entendimento de que aquilo que é social é exógeno à saúde pública, como se a questão social, suas expressões e suas macrodeterminações não fossem parte da saúde. Assim, o que requer uma intervenção social não se mostra como algo en- 
dógeno ao campo da saúde. É tratado como uma externalidade. É como se existisse uma porta imaginária dentro das unidades de saúde que dividissem o biológico e o social, devendo o usuário atravessar essa porta ou não passar por ela. $\mathrm{O}$ que é social então aparece como algo "diferente" e isolado da saúde e seu campo duro de saber.

Daí então que as ações de promoção à saúde são consideradas indicadores importantes para os gestores das Secretarias Municipais de Saúde para mostrar uma prática social de trabalho com a saúde coletiva. Todavia, quando acontece a divisão do trabalho em equipe, aquele trabalho que condensa a prática do diálogo com a comunidade, este mesmo trabalho é considerado algo menor, com indicadores não muito claros, metas não muito rígidas a serem alcançadas pelos profissionais da estratégia de saúde da família. Isto porque esse trabalho de promoção da saúde não pertence à saúde no seu campo duro (químico e biológico) de saber.

Por outro lado, o assistente social cumpre um papel fundamental de responder a demandas que se relacionam à dimensão local do território: atender vítimas de violência velada ou visíveis e encaminhá-las a serviços específicos, abandono de idosos, maus-tratos a crianças ou mulheres em situação de vulnerabilidade social ou a pobreza que se expressa na "falta de" — uma dimensão capturada nas visitas domiciliares.

Encontramo-nos, portanto, em outra dimensão do trabalho do assistente social nas unidades de saúde: a sua aproximação ao trabalho do agente comunitário de saúde. Logo no início da implantação da estratégia de saúde da família pelo Ministério da Saúde, o Serviço Social, por meio do seu órgão de representação de classe, questionou a inserção do assistente social como "equipe de apoio" à "equipe básica" nas unidades de saúde. Essa distinção fez permanecer uma separação preexistente ao modelo de intervenção com famílias. Questionava-se o isolamento do Serviço Social dentro da divisão do trabalho em equipe, questionava-se o instrumental subutilizado do assistente social na abordagem com famílias (visto que era uma estratégia de saúde da família) e, ainda, o trabalho de visita domiciliar - tão característico da prática do Serviço Social — atribuído então para um segundo profissional, de nível médio de escolaridade, o agente comunitário de saúde.

Atualmente, essa divisão do trabalho dentro das unidades faz com que o assistente social e o agente comunitário de saúde realizem a visita domiciliar. $\mathrm{O}$ primeiro, o assistente social, com a intenção de esclarecer informações que não estejam tão evidentes para subsidiar o seu processo de intervenção, parecer social ou trazer novos dados e informações para a equipe de saúde como um todo, buscar 
novos subsídios sobre o acompanhamento de um caso ou algo que não tenha sido dito claramente após a reunião de um grupo. O segundo, o agente comunitário, utiliza a visita domiciliar como uma captura de dados, coleta de informações delimitadas previamente e organizadas em dezenas de questionários que devem ser aplicados e preenchidos de forma correta. Será o agente comunitário que trará a informação primeira, o dado bruto a ser trabalhado pela equipe, suas impressões, sua observação sobre a realidade. Ou seja, espera-se desse agente comunitário um olhar sensível sobre a realidade de saúde que subsidiará a intervenção da equipe que acontecerá a posteriori.

O fato é que a visita domiciliar tornou-se uma ferramenta comum para ambos, e no jogo das relações de trabalho os agentes comunitários de saúde observam as visitas feitas pelos assistentes sociais como um trabalho a menos a ser realizado por eles. Uma vez que o assistente social tenha visitado determinada família, considera-se uma a menos para o agente comunitário abordar, e isso se torna um motivo de conflito a ser resolvido pelas gerências dos serviços.

A proposta das visitas domiciliares é diferente em sua essência. Contudo, quem acaba perdendo com esse processo de trabalho assim organizado é o usuário do serviço de saúde que tem sua casa "aberta" para os profissionais de saúde várias vezes, passivo a uma intervenção que ele ainda não sabe no que resultará. Assim, a visita domiciliar se torna um procedimento invasivo do assistente social e do agente comunitário de saúde, objetivando uma intervenção rotineira ao âmbito mais privado da vida: a residência e os hábitos domésticos de comportamentos. Nas casas das famílias mais pobres isso se torna um procedimento corriqueiro, e os profissionais de saúde veem essas famílias como pessoas que "devem" abrir as portas das suas casas para a intervenção dos profissionais em nome do SUS e em nome do Estado.

Em um comparativo, os profissionais relatam que nas casas de famílias de classe média ou com renda mais alta em bairros considerados ricos, existe grande dificuldade de entrar nas casas das pessoas, visto que nem sempre permitem ou julgam não ser necessário. Por outro lado, os assistentes sociais avaliam que as famílias mais pobres permitem sua entrada de forma cortês. Os profissionais então rotulam que essas famílias são mais "educadas", pois abrem suas portas e entendem o procedimento de entrada da equipe em suas casas.

A visita domiciliar é uma ferramenta apontada pelos assistentes sociais como subsidiária ao trabalho de promoção da saúde, pois ela proporciona a coleta de uma informação em estágio avançado a ser trabalhado pelo Serviço Social, quando a informação não está clara e o parecer social está ainda obscuro. Desta forma, re- 
sulta da visita um "esclarecimento" de algo que o assistente social pressupunha ou não tinha informação alguma.

Alguns profissionais chegam a declarar que não consideram a visita domiciliar uma ferramenta da promoção da saúde, pois ela se confunde com um "trabalho de polícia". A visita algumas vezes funciona como a busca por uma prova ou evidência sobre um hábito, um comportamento ou uma atitude que será combatida pelo assistente social. Associam-se a isso o abandono de crianças, o envolvimento com tráfico de drogas, violência contra mulheres, maus-tratos em caso de transtornos mentais, higiene (individual ou no âmbito dos cuidados da casa), alimentação inadequada a doentes ou idosos que demandam cuidados. Nesses casos, o assistente social tem sua prática de visita domiciliar legitimada como "autoridade sanitária" na investigação dos casos que se manifestam como uma expressão da questão social. Contudo, essas "descobertas" feitas por meio de um trabalho denominado de "investigação" pelos assistentes sociais não são consideradas atividades de promoção da saúde, realizadas, muitas vezes, com incerteza pelos profissionais. Pois produz um questionamento sobre o limite tênue da visita domiciliar associado ao trabalho de policiar, inquirir, investigar a vida dos usuários da saúde pública. Alguns profissionais, em situações mais graves, preferem não realizar o trabalho de visita domiciliar, tamanho o envolvimento de determinada família com o tráfico de drogas — o que implica a segurança de suas próprias vidas.

A diferença desse trabalho realizado pelo assistente social e o agente comunitário está, também, na contagem dessa produção. O assistente social habitualmente não tem um número a ser perseguido em suas visitas domiciliares. $\mathrm{O}$ agente comunitário, sim. Daí que a visita realizada pelo assistente social tem uma flexibilidade que o agente comunitário não possui. Portanto, ela passa a ser mais dialogada, não preocupada com o tempo ou com um número de questionários a ser preenchidos. Desta forma, a dimensão dessa produção, ganha em qualidade e se difere do trabalho medido pela quantidade.

O produto final da visita resulta em um relatório que pode vir a subsidiar um parecer social para o Juizado da Infância e Juventude, servir de encaminhamento para um centro de referência de assistência social ou resposta a um questionamento do ministério público - uma demanda que a equipe considerada "básica" de saúde não quer para si. E esse trabalho não consta nos boletins de produtividade das unidades de saúde para as Secretarias Municipais, nas metas estabelecidas pelo Ministério da Saúde e não é "contabilizado" pelos assistentes sociais. Muitos profissionais possuem um controle interno dessa produção e guardam consigo, até em armários próprios, os pareceres e relatórios gerados pelo Serviço Social. 


\section{Considerações finais ou a saúde como produção de vínculos}

O olhar biomédico que demarca a questão social como exógena à saúde delimita uma segmentação do trabalho social demarcado, contraditoriamente, pela produção de vínculos com o usuário. Será esse o diferencial do trabalho produzido pelo assistente social. A escuta que acolhe ou o uso de uma linguagem que produza afetação no usuário do serviço de saúde é o que resulta em uma prática que envolve e tece relações diretamente com os usuários.

Os assistentes sociais usam da linguagem como sua principal ferramenta no encontro com os usuários do SUS através da atenção primária à saúde. Percebem que é a dinâmica de produzir subjetivação nas relações sociais que envolve e politiza o encontro entre o assistente social e o usuário. Usam de recursos que se baseiam majoritariamente na escuta que acolhe, nas orientações que reorganizam o raciocínio, na tradução de informações técnicas e burocráticas para uma ação que direciona para a produção do acesso às políticas sociais. Essa forma de receber o usuário produz vínculo, acolhimento e tradução.

Observamos que a palavra "vínculo" no seu sentido etimológico pode significar conexão, junção, ligamento, amarração. E é exatamente nesse sentido que queremos fazer uso da palavra. Observamos que os usuários da estratégia de saúde da família muitas vezes se relacionam com o assistente social em uma relação de espelhamento. Veem nele a possibilidade de ser acolhidos e depositam nesse profissional uma vinculação que produz um elo de corresponsabilidade sobre questões mais intimistas de suas vidas.

Quando visitados ou entrevistados por um profissional de Serviço Social vocalizam demandas que não são conotativas de uma doença ou acompanhamento de algum tratamento apenas. $\mathrm{O}$ atendimento individual do assistente social habitualmente é realizado de portas fechadas, em uma relação que resguarda o sigilo. Não pela preocupação em mostrar o corpo sem roupa ou o uso de um medicamento injetável, mas pela linguagem verbalizada que é dialogada de forma direta entre assistente social e usuário, abrindo códigos e informações somente direcionadas a um profissional que a população julga "recebedora" dessa relação de confiança. De forma rotineira, os usuários são correspondidos nessa relação.

O trabalho de escuta e produção de vínculo promove a saúde dos usuários, e os assistentes sociais têm clareza disto. Este trabalho do diálogo, da atenção, orientação e escuta é um trabalho que não atende a indicadores ou metas a serem alcançadas por gestores dos serviços de saúde, pois não são contabilizados como algo calculável. Por um lado, isso não proporciona visibilidade ao trabalho do assisten- 
te social nas "métricas" administrativas de gerenciamento dos serviços de saúde. Por outro lado, evidencia a potência da ação desse profissional. No encontro com os usuários (individual ou coletivamente), esse trabalho não é controlado (ou capturado) por dentro de sua dinâmica. O produto em decorrência do atendimento realizado pelo assistente social é potente pelos seus resultados, pois é fruto de um trabalho que se dá em ato, por meio de uma relação direta com os usuários, argumentado e fundamentado em ferramentas que são dialógicas. Neste sentido, gera um produto livre de amarras produtivistas - ainda que as gerências tentem colocar esse trabalho subordinado a indicadores estatísticos ou epidemiológicos.

Daí que o assistente social percebe que sua principal ferramenta (a linguagem) gera um produto vital: a ação orientada, com perspectivas de continuidade da vida, para além do discurso da doença, uma promoção da saúde no seu sentido lato. Esta, então, se torna a dimensão política do seu trabalho — uma política que produz mais relações sociais, no sentido de arregimentar, agregar relações humanas para perspectivar a continuidade da vida. Neste sentido, afirmamos que este trabalho, que é relacional, é potente em sua ação.

Recebido em 23/9/2013 - Aprovado em 2/12/2013

\section{Referências bibliográficas}

BUSS, P. M. Uma introdução ao conceito de promoção da saúde. In: CZERESNIA, D.; FREITAS, C. M. (Orgs.). Promoção da saúde: conceitos, reflexões, e tendências. Rio de Janeiro: Fiocruz, 2003.

COSTA, J. F. Ordem médica e norma familiar. 5. ed. Rio de Janeiro: Graal, 2004.

CZERESNIA, D. O conceito de saúde e a diferença entre prevenção e promoção. In:

FREITAS, C. M. (Orgs.). Promoção da saúde: conceitos, reflexões, tendências. Rio de Janeiro: Fiocruz, 2003.

FOUCAULT, M. Microfísica do poder. 15. ed. Rio de Janeiro: Graal, 2000.

SANTOS, Keli Lopes; QUINTANILHA, Bruna Ceruti; DALBELLO-ARAÚJO, Maristela. A atuação do psicólogo na promoção da saúde. Psicol. Teor. Prat., São Paulo, v. 12, n. 1, 2010. Disponível em: $<\mathrm{http}: / /$ pepsic.bvsalud.org/scielo.php?script=sci_arttext\&pid=S1516368720 $10000100015 \& \operatorname{lng}=$ pt\&nrm=iso $>$. Acesso em: 16 set. 2013. 